\section{Response: Re: Dry Needling in the Management of Musculoskeletal Pain}

\author{
Simon Vulfsons, $M D$, and \\ Leonid Kalichman, PT, PhD
}

To the Editor: We congratulate Dr. Kent for having worked with Dr. Chan Gunn for 25 years. In the study published by Ceccherelli et al, ${ }^{1}$ the comparison was made between superficial and deep dry needling for patients suffering from low back pain (LBP) of myofascial origin. In the Methods section of their article, the authors state that the needles used were "(1) 34.30 needles (useful length of the needle, $18 \mathrm{~mm}$ ) for superficial insertion; (2) 52.30 (useful length of the needle, $29 \mathrm{~mm}$ ) for deep insertion when the subcutaneous area is up to $1.5 \mathrm{~cm}$ thick; and (3) 72.40 (useful length of the needle, $49 \mathrm{~mm}$ ) for deep insertion when the subcutaneous area is at least $3 \mathrm{~cm}$ thick." This will give 18 to $19 \mathrm{~mm}$ of effectual intramuscular needle length. In fact, the authors claim that the actual intramuscular stimulation length of the needles was approximately $1.5 \mathrm{~cm}$, which is perfectly plausible.

Although this article was specifically focused on dry needling for myofascial pain in the whole body and not just the low back, we agree with Dr. Kent that classification of LBP has become one of a "waste basket" issue. Unfortunately some authors classify according to specific and nonspecific causes of LBP, where by definition the nonspecific causes are nondiagnosable. ${ }^{2,3}$ This approach invalidates myofascial physical examination, which is, according to some authors, not reliable. To our dismay, we even find soft tissue palpation being dumped as "worthless." It would be worth anyone's time to read the excellent chapters about diagnosis in Dummerholt's and Huijbregts's ${ }^{4}$ book Myofascial Trigger Points to realize the reliability of soft tissue palpation after appropriate training.

The treatment of myofascial trigger point (MTrP) pain is dependent on the release of the point, the reduction of pain, and the restoration of normal function. On this there is agreement. Where there is disagreement is on the etiology of MTrP generation. The central premise of Travell and Simons ${ }^{5}$ has been that an "adenosine triphosphate energy crisis" has caused the development of MTrPs. Simons ${ }^{6}$ implicated the motor endplate as the central etiology of these points. Although motor endplate dysfunction is clearly at the heart of myofascial pain, Gunn ${ }^{7}$ proposes that the reason that the endplates are dysfunctional is because of neuropathic nervous dysfunction causing target organ (in this case, muscle) supersensitivity. Is it only the endplate or is it supersensitivity? This discussion is beyond the scope of this response, but should be addressed in further detail in future studies.

Simon Vulfsons, MD

Pain Relief Unit, Rambam Health Care Campus Rappaport School of Medicine Technion, Haifa, Israel Leonid Kalichman, PT, PhD

Department of Physical Therapy, Recanati School for Community Health Professions, Faculty of Health Sciences, Ben-Gurion University of the Negev Beer Sheva, Israel. kalichman@hotmail.com.

\section{References}

1. Ceccherelli F, Rigoni MT, Gagliardi G, Ruzzante L. Comparison of superficial and deep acupuncture in the treatment of lumbar myofascial pain: a double-blind randomized controlled study. Clin J Pain 2002;18:149-53.

2. Deyo RA, Weinstein JN. Low back pain. N Engl J Med 2001;344:363-70.

3. Koes BW, van Tulder MW, Thomas S. Diagnosis and treatment of low back pain. BMJ 2006;332:1430-4.

4. Dommerholt J, Huijberts P. Myofascial trigger points: pathophysiology and evidence-informed diagnosis and management. Sudbury, MA: Jones and Bartlett; 2011.

5. Simons DG, Travell JG, Simons LS. Travell and Simons' myofascial pain and dysfunction: the trigger point manual. Volume 1, 2nd ed. Baltimore, MD: Williams \& Wilkins; 1999.

6. Simons DG. Clinical and etiological update of myofascial pain from trigger points. J Musculoskel Pain 1996;4:97-125.

7. Gunn CC. Radiculopathic pain: diagnosis, treatment of segmental irritation or sensitization. J Musculoskel Pain 1997; 5:119-34.

doi: 10.3122/jabfm.2011.01.100252 